\title{
Evaluation of the Association Between Carotid Intemia-Media Thickness and Myocardial Infarction
}

\author{
Asgad A Abdalgbar ${ }^{1,2}$ and Hanan G K Altalhi ${ }^{1 *}$ \\ ${ }^{1}$ Department of Medicine, University of Omar El mukhtar, Libya \\ ${ }^{2}$ Department of Medical Technology, University of Omar El Mukhtar, Libya \\ *Corresponding author: Hanan G K Altalhi, Department of Medicine, University of Omar El mukhtar, Albayda- Libya. \\ To Cite This Article: Hanan G K Altalhi, Evaluation of the Association Between Carotid Intemia-Media Thickness and Myocardial Infarction. Am J \\ Biomed Sci \& Res. 2019 - 6(3). AJBSR.MS.ID.001026. DOI: 10.34297/AJBSR.2019.06.001026.
}

Received: 眥 November 02, 2019; Published: 眥 November 22, 2019

\begin{abstract}
Background: The combined thickness of intima and media of carotid artery is associated with prevalence of cardiovascular disease. We studied the association between the thickness of carotid artery intima and media and the incidence of new myocardial infarction in person without clinical evidence of cardiovascular disease.

Patients and Methods: This is case control study of 26 patients admitted to the hospital with acute myocardial infarction (case subject), and 26 patients without acute myocardial infarction (control subjects). All the participant underwent the standard examination and testing, as well as B - Mode ultrasound (US measurements of right and left common carotid artery IMT and internal carotid arteries IMT were made). Diabetic patients and those with peripheral vasculopathy and cerebral vasculopathy were excluded from the study.

Result: The mean maximum IMT of the CCA, ICA were significantly higher in study group than among the control group $(\mathrm{P}=0.05, \mathrm{P}=0.002$, respectively).

Conclusion: Intima-media thickness of the common carotid and ICA as assessed by ultrasonography was significantly greater in patients with acute myocardial infarction.
\end{abstract}

Keywords: Myocardial infarction; Intima-media thickness (IMT); Ultrasonography; Common carotid artery (CCA); Internal carotid artery (ICA)

\section{Introduction}

Carotid ultrasonography has been used to obtain measurement of thickness of intima -media of the carotid artery (IMT), presences of plaques and presences of stenosis [1] (Veller MG et al .1993). The IMT corresponds to the intima - media complex, which comprises endothelial cells, connective tissue, and smooth muscle and is the site of lipid deposition in plaque formation (Salonen JT .1993). In healthy adults, IMT ranges from 0.25 to $1.5 \mathrm{~mm}$ (Veller rMG, et al.1993) [2]. and values $>1.0 \mathrm{~mm}$ are often regarded as abnormal (Solnen JT, et al. 1993).

IMT has been proposed as quantitative index of atherosclerosis of value in monitoring disease progression and the effects of treatment and as a surrogate end points in clinical trial [3].

\section{Aim of the work}

We investigated whether carotid intima - media thickness measured by noninvasive B-mode ultrasonography is associated with incidence of myocardial infarction in adults 40 to 65 years of age or older without preexisting cardiovascular $r$ disease.

\section{Patients and Methods}

This is case control study of patients admitted to the hospital with diagnosis of acute myocardial infarction (AMI), (40 to 65 years of age), and patients without acute myocardial infarction admitted for other reason to the hospital were included as control group, with no previous history of cardiac pathology, aged 40 to 65 year who underwent exercise testing with normal result. Patients with up to 1 risk factor such as systemic arterial hypertension, smoking or dyslipedemia were accepted in control group [4]. The following patients were excluded from the study; those undergoing carotid artery surgery, those with diabetes, with peripheral vasculopathy, stroke, bypass surgery or angioplasty and aortic valve disease, absence of acoustic window. 
The following data were obtained either with an interview or through analysis of the medical record: name, age,(year), address, telephone, sex, smoking , habit, presence of dyslipedimia, familial history, systemic arterial hypertension, hormone replacement, use of drugs with cardiovascular or lipid lowering effects, previous cardiac surgery, previous cine coronary angiography, previous coronary angioplasty, and previous acute myocardial infarction [5]. All participants underwent the stander examination and testing. Acute myocardial infarction (AMI) was diagnosed based on recently adopted definition of AMI by ACC /AHA /ESC / WHF task force [6]. ST elevation myocardial infarction was defined as typical rise and fall in CK - -MB (usually twice the level of upper reference limit) and at least one $\mathrm{mm}$ ST rise in two contiguous limb leads or $2 \mathrm{~mm}$ rise in two chest leads.

Carotid ultrasound to be done using a 7.5 MHz linear- array transducer, single trained physicians conducted the ultrasound and interpreted the results. On longitudinal, two - dimensional ultrasound image of the carotid artery, the anterior (near) and the posterior (far) walls of the carotid artery are displayed as two bright white lines separated by a hypoechogenic space. The distance between the leading edge of the first bright line of the far wall (lumen - intima interface). And the leading edge of the second bright line (media-adventitia interface) indicates the intima - media thickness. For the near wall, the distance between the trailing edge of the first bright line and the trailing edge of the second bright line at the near wall provides the best estimate of the near- wall intima - media thickness. In accordance with the Rotterdam study ultrasound protocol [2].

The ICA was defined as including the carotid bulb, identified by loss of parallel wall present in the CCA, and $10 \mathrm{~mm}$ segment of the ICA distal to the tip of the flow divider. To quantify the degree of thickening of carotid artery walls, we assessed the maximum IMT. Maximum IMT of CCA and ICA was defined as single thickest wall of near and far right or left wall of the CCA. A Composite measure that combined the maximal common carotid artery Intima - media thickness and maximal internal carotid artery intemia media thickness was obtained by averaging these two measurements after standardization (subtraction of the mean and division by the standard deviation for the measurements) [7].

\section{Other Various Factors}

Blood pressure measurement in the right arm, cigarette smoking to be quantified based on daily consumption and duration of smoking, blood biochemistry analysis was made i.e., fasting blood glucose (FBS), total cholesterol, LDL, HDL, TG.

\section{Statistical Analysis}

Statistical analysis was performed by using SPSS software (version 11), difference among groups were analyzed by one-way unstuck ANOVA and P values 0.05 were considered significant.

\section{Result}

(Table 1) 52 patients were included in the study, 26 patients with acute MI (case group) and 26 patients without MI (control group). There is significant difference in mean age between case group and control group (P 0.07). There is no significant difference in the distribution and frequency of hypertension among groups. All smoker was male without significant difference among groups.

\begin{tabular}{|c|c|c|c|}
\hline \multicolumn{3}{|c|}{ Table 1: Study population characteristics and variations. } \\
\hline & MI group & Control group & P value \\
\hline Age mean \pm SD & $54 \pm 7$ & $48 \pm 7$ & 0.07 \\
\hline Rang & $43-65$ & $40-65$ & \\
\hline Number & 26 & 26 & \\
\hline Male & $14(53.8 \%)$ & $17(65.4 \%)$ & 0.406 \\
\hline Female & $12(46.2 \%)$ & $9(34.6 \%)$ & 0.406 \\
\hline Hypertension & $8(30.8 \%)$ & $4(15.4)$ & 0.162 \\
\hline Smoking & $9(34.6 \%)$ & $11(42.2 \%)$ & 0.724 \\
\hline
\end{tabular}

(Table 2) Mean maximum IMT of the CCA and ICA were significantly higher in MI group than control group $(\mathrm{P}=0.05$, $\mathrm{P}=0.002$ respectively.

\begin{tabular}{|c|c|c|c|}
\hline \multicolumn{4}{|c|}{ Table 2: Clinical Laboratory and Ultrasound data of study group. } \\
\hline & MI Group & Control Group & P value \\
\hline Initial SBP & $149.15 \pm 36.65$ & $148.08 \pm 37.31$ & 0.917 \\
\hline Initial DBP & $92.69 \pm 25.07$ & $88.27 \pm 16.31$ & 0.454 \\
\hline Cholesterol & $169.08 \pm 49.69$ & $160.23 \pm 37.70$ & 0.588 \\
\hline Triglycerides & $91.33 \pm 25.88$ & $102.14 \pm 42.12$ & 0.299 \\
\hline $\begin{array}{c}\text { Maximum CCA } \\
\text { IMT mm }\end{array}$ & $1.22 \pm 0.35$ & $1.02 \pm 0.21$ & 0.05 \\
\hline $\begin{array}{c}\text { Maximum ICA } \\
\text { IMT mm }\end{array}$ & $1.97 \pm 0.93$ & $1.57 \pm 0.76$ & 0.002 \\
\hline Smoking & $9(34.6 \%)$ & $11(42.2 \%)$ & 0.724 \\
\hline
\end{tabular}

\section{Discussion}

The present study demonstrated that the increased maximum IMT of CCA and ICA are strong predicator for risk of myocardial infarction. Sever cross sectional studies have shown that increase common carotid intima - media thickness confers an increased risk of cardiovascular disease $[2,4,8,9]$. Some study has shown that an increased maximum common carotid intima - media thickness is related to an increased risk of myocardial infarction [10-12]. Prospective follow up studies have recently been initiated in which B-mode ultrasonography of carotid arteries provide for evaluation of lumen diameter, intima - media thickness and presence and extent of plaques [2,13-15]. An increased cross-sectional carotid intima - media thickness was associated with unfavorable level of established cardiovascular risk factor [2,13-15]. Limited number of interventions showed reduced progression of intima -media thickness in subjects treated with lipid lowering drugs compared with placebo group $[3,16,17]$. 


\section{Conclusion}

We conclude that the wall thickening of the CCA and ICA as assessed by noninvasive ultrasonography are positively associated with an increased risk of myocardial infarction.

\section{References}

1. Belcaro G, Nicolaids AN, Laurora G, Cesarone MR, DeSanctis M, et al (1996) Ultrasound morphology calcification of the arterial wall and cardiovascular events in a 6- year follow - up study. Arterioscler thromb vas Bio 16: 851-856.

2. Bots Ml, Witteman JCM, Grobbee De (1993) Carotid intima - media wall thickness in elderly women with and without atherosclerosis of the abdominal aorta. Atherosclerosis 102(1): 99-105.

3. Crouse JR III, Byington RP, Bond MG, Espeland MA, Craven TE, et al. (1995) Pravastatin, lipids, and atherosclerosis in the carotid arteries (PLAC-II). AMJ Cardiol 75(7): 455-459.

4. Bots ML, Hofman A, Grobbee DE (1995) Common carotid intima-media thickness and cardiovascular disease in the Rotterdam study: acrosssectional analysis. In: Koenig W, Hombach V, Bond MG, Kramsch DM, eds. Progression and Regression of Atherosclerosis. Vienna, Austria: Blackwell Scientific Publisher Pp.118-123.

5. Shah EB, Olia PA, Peter WH, Goya WA, Mary WA, et al. (1999) Carotid plaque, Intima Media Thickness, Cardiovascular Risk Factors, and Prevalent cardiovascular disease in men and women. Stroke 30(4): 841850.

6. Thygesen K, Alpert JS, White HD (2007) Universal definition of myocardial infarction. JA Coll cardiol 50(22): 2173-2195.

7. O Leary DH, Polak JF, WolfsonSK, Bond MG, Bommer W, et al. (1991) CHS Collaborative Group. Use of Ultrasonography to evaluate carotid atherosclerosis in the elderly: The Cardiovascular Health study. Stroke 22:1155-1163.

8. Bots ML, Hofman A, Grobbee DE (1994) Common carotid intima-media thickness and lower extremit arterial atherosclerosis: the Roterdam study. Arterioscler Thromb 14: 1885-1891.
9. Polak JF, OLeary DH, Kornmal RA, Wolfson SK, Bond MG, et al. (1993) Sonographic evaluation of the carotid artery atherosclerosis in the elderly: relationship of disease severity to stroke and transient ischemic attack. Radiology 188(2): 363-370.

10. Salonen R, Salonen JT (1991) Determinants of carotid intima-media thickness: apopulation -based ultrasonography study in eastern Finnish men. J Intern Med 229(3): 225-231.

11. Salonen JT, Slonen R (1991) Ultrasound B-mode imaging in observational studies of atherosclerotic progression. Circulation 229: 225-231.

12. Michiel L Bots, Arno W Hoes, Peter J Koudstaal, Albert Hofman, Diederic E Grobbee (1997) Common carotid intima-media thickness and risk of stroke and myocardial infarction: the Rotterdam Study. Circulation 96(5): 1432-1437.

13. Heiss G, Sharett AR, Barnes R, Chambiess LE, SzkloM, et al. (1991) Carotid atherosclerosis measured by B-mode ultrasound in population: association with cardiovascular risk factors in the ARIC study. Am J Epidemiol 134(3): 250-256.

14. Wendelhag I, Olov G, Wikstrand J (1992) Arterial wall thickness in familial hypercholesterolemia: ultrasound measurement of intimamedia thickness in the common carotid artery. Arterioscler thromb 12(1): 70-77.

15. Psaty BM, Furberg CD, Kuller LH, Borthani NO, Rautaharju PM, et al. (1992) Isolated systolic hypertension and subclinical cardiovascular disease in the elderly: initial finding from cardiovascular Health Study. JAMA 268(10): 1287-1291.

16. Blankenhorn D, Selzer RH, Crawford DW, Barth JD, Liu C, et al. (1993) Beneficial effects of colestipol - niacin therapy on the common carotid artery; two - and four - year reduction of intima - media thickness measured by ultrasound. Circulation. 88(1): 20-28.

17. Furberg CD, Adams HP, Applegate WB, Byington RP, Espel d anMA, et al. (1994) Effect of lovastatin on early carotid atherosclerosis and cardiovascular events. Circulation 90(4): 1679-1687. 